\title{
Article \\ Effect of Divided Exhaust Period in a High Efficiency TGDI Engine
}

\author{
Heechang Oh ${ }^{1, *}$, Dongwon Jung ${ }^{1}$, Jinwook Son ${ }^{1}$, Soohyung Woo ${ }^{1}$, David Roth ${ }^{2}$, Jerry Song ${ }^{3}$, \\ Youngmyung Kweon ${ }^{4}$ and Joonsik Hwang ${ }^{5}$ \\ 1 R\&D Division, Hyundai Motor Company, Hwaseoung-si 18290, Gyeonggi-do, Korea; \\ great0526@hyundai.com (D.J.); jwson@hyundai.com (J.S.); qwerty@hyundai.com (S.W.) \\ 2 Roth Engine Science LLC, Groton, NY 13073, USA; droth6189@gmail.com \\ 3 Navistar Inc., Lisle, IL 60532, USA; bjsong@ieee.org \\ 4 BorgWarner Chungju, Chungju-si 27465, Chungcheongbuk-do, Korea; ymkweon@borgwarner.com \\ 5 Department of Mechanical Engineering, Mississippi State University, Starkville, MS 39762, USA; \\ hwang@me.msstate.edu \\ * Correspondence: hcoo@kaist.ac.kr
}

Citation: Oh, H.; Jung, D.; Son, J.; Woo, S.; Roth, D.; Song, J.; Kweon, Y.; Hwang, J. Effect of Divided Exhaust Period in a High Efficiency TGDI Engine. Energies 2021, 14, 6343. https://doi.org/10.3390/en14196343

Academic Editor: Roberto Cipollone

Received: 20 August 2021

Accepted: 26 September 2021

Published: 4 October 2021

Publisher's Note: MDPI stays neutral with regard to jurisdictional claims in published maps and institutional affiliations.

Copyright: (c) 2021 by the authors. Licensee MDPI, Basel, Switzerland. This article is an open access article distributed under the terms and conditions of the Creative Commons Attribution (CC BY) license (https:/ / creativecommons.org/licenses/by/ $4.0 /)$.

\begin{abstract}
The divided exhaust period (DEP) concept was applied to a high-efficiency gasoline engine and its impact on various engine performance aspects were investigated. To this end, key design parameters of DEP components were optimized through 1-D engine simulation. The designed DEP components were fabricated and experimental verification was performed through an engine dynamometer test. The developed DEP engine shows suitable performance for electrified vehicles, with a maximum thermal efficiency of $42.5 \%$ as well as a wide sweet spot area of efficiency over $40 \%$. The improvement in thermal efficiency was mainly due to a reduction in pumping loss. Notably, the reduction in pumping loss was achieved under high exhaust gas recirculation (EGR) flow conditions, where further improvements in fuel consumption could be achieved through a synergistic combination of DEP implementation and high dilution combustion. Furthermore, a significantly improved catalyst light-off time, uncharacteristic in turbocharged engines, was confirmed through a simulated cold-start catalyst heating engine test.
\end{abstract}

Keywords: divided exhaust period (DEP); turbocharged gasoline direct injection (TGDI); exhaust gas recirculation (EGR); gasoline engine; dedicated hybrid engine (DHE); high efficiency

\section{Introduction}

Since the time that strict emission and fuel consumption regulations were initiated, automobile manufacturers have been trying to minimize $\mathrm{CO}_{2}$ emissions all over the world. As a strategy to meet the regulations, manufacturers are increasing the volume of battery electric vehicles and fuel cell electric vehicles [1,2]. In addition to these zero tail-pipe emission vehicles, hybrid electric vehicles (HEVs), which have both an internal combustion engine (ICE) and an electric propulsion system, are also regarded to be the important solution for the cleaner powertrain technology and are expected to have larger market shares in the future [3-6]. Since HEVs can synergize with carbon-neutral fuels and serve as a sustainable powertrain for the long-term future [4,7], ICE can remain as an attractive part of the future powertrain based on its cost-effective competitiveness [8,9]. Therefore, the research and development of ICE to have higher thermal efficiency and lower exhaust emissions will still be important.

Engine downsizing is one of the important technologies, most actively applied to gasoline engines over the past few decades. The main concept is to replace large displacement naturally aspirated (NA) engines with smaller displacement boosted engines that meet the required power output performance. This technology began to be actively deployed along with significant improvement of low-end torque (LET) through scavenging, 
which was realized by the combination of gasoline direct injection (GDI) and turbocharging technology [10-12]. The improved LET can also realize engine down-speeding with the lowered transmission gear ratio, thereby significant fuel consumption improvement of the vehicle could be achieved by shifting engine operation points to the favorable sweet spot region. In addition, it has advantages in terms of the dynamic performance of the vehicle, vehicle weight, and engine room space as well. Accordingly, turbocharged downsizing engines have been introduced into the market considerably from this period, and they are currently positioned as one of the mainstream technologies [13].

However, with the current rapid trend of electrification in the automotive sector, the role and the requirement of ICEs are changing significantly, and the aspects of related engine technology are also changing. In particular, technologies such as the heavily downsizing engine strategy have lost benefits and have limited application due to changes in engine requirements and tighter exhaust emission regulation. In particular, the combinations with hybrid or mild hybrid are expected to be essential for future engines, the benefits of low-load efficiency technologies diminish, and it becomes less important to meet various development requirements for a wide range of engine operating conditions $[6,9,14]$. In contrast, achieving high thermal efficiency in the sweet spot becomes a more important engineering target for state-of-the-art engines, specially dedicated hybrid engines (DHEs). For these engines, synergistic combinations of higher expansion ratio, such as the Atkinson or Miller cycle and highly dilute combustion technology represented by exhaust gas recirculation (EGR), have usually been applied to improve thermal efficiency [15-17].

Meanwhile, a divided exhaust period (DEP) technology has been studied as an effective approach for improving fuel efficiency and performance of turbocharged engines. The original idea of the technology started with a British patent in 1924 and has been investigated up to these days as introduced well in previous studies [18-21]. The schematics presenting the configuration and basic principle of the DEP engine are shown in Figure 1. As shown in Figure 1a, the DEP engine has separated exhaust flow paths for each exhaust valve of the cylinder, where the only blow-down port is attached to the turbocharger's turbine inlet and the scavenging port connects directly with the catalytic converter. Exhaust valve events are also separately operated for each valve, as shown in Figure 1b. The valve events for the blow-down port are biased towards the earlier phase of the exhaust process, which occurs directly after the opening of the exhaust valve. This blow-down period is primarily driven by the pressure difference between the combustion chamber and upstream of the turbine. The exhaust enthalpy to run the turbine is supplied from this period. Therefore, it is known that exhaust energy delivered to the turbine can be comparable to conventional turbocharged engines, while it has the advantage of reduced exhaust interference due to the short duration of the blow-down period [18]. On the other hand, the valve event for the scavenging period shown in Figure $1 \mathrm{~b}$ is biased towards the latter phase of the exhaust process, which is called a scavenging period. During the scavenging period, the exhaust flow is primarily driven by the displacement of the piston, ending in the vicinity of the top dead center (TDC) as the exhaust valve closes. Since the scavenging path is directly connected to the catalytic converter bypassing the turbine, the in-cylinder pressure at exhaust valve close (EVC) is equal to the pressure upstream of the catalytic converter (P3) which is lower than the pressure at the turbine inlet (P2). This results in lower pumping loss and a residual gas fraction (RGF) compared to conventional turbocharged engines where the in-cylinder pressure at EVC is related to P2. In addition, it is reported in earlier studies $[21,22]$ that, since the scavenging period contains three to five times more unburned hydrocarbon (UHC) emissions than the blowdown period, the application of scavenging sourced EGR can improve combustion efficiency through re-burn of UHC emissions. Thanks to many advantages as described, DEP technology has been investigated in both spark ignition (SI) engines [18,19,21-25] and compression ignition (CI) engines [20,26]. 


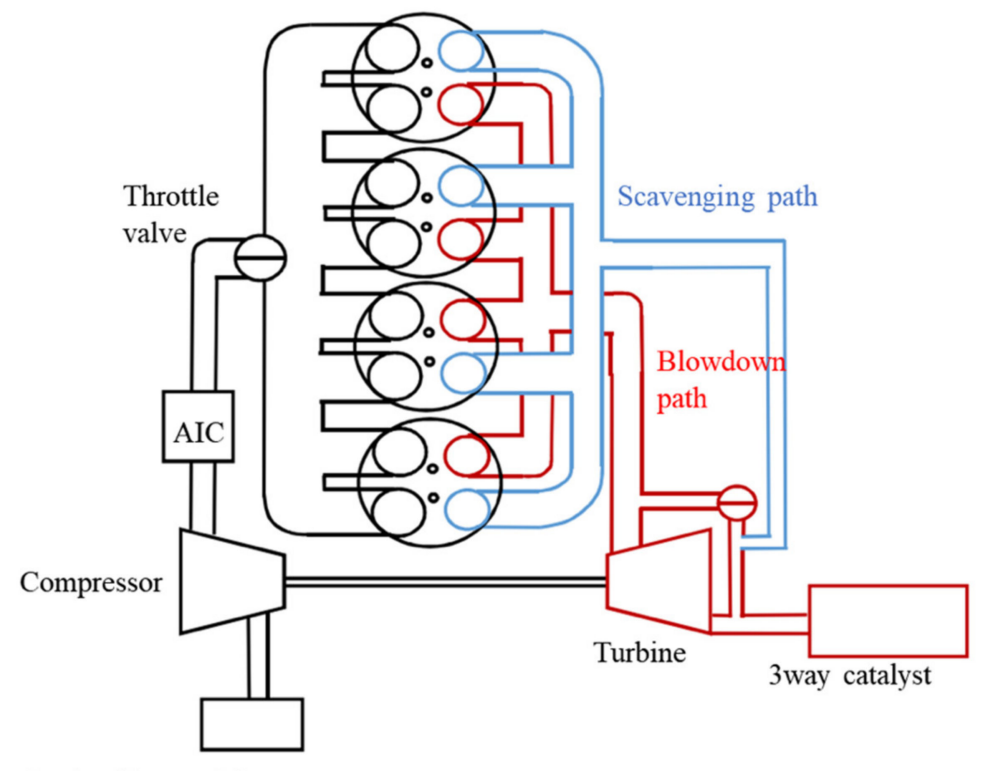

Intake filter and duct

(a)

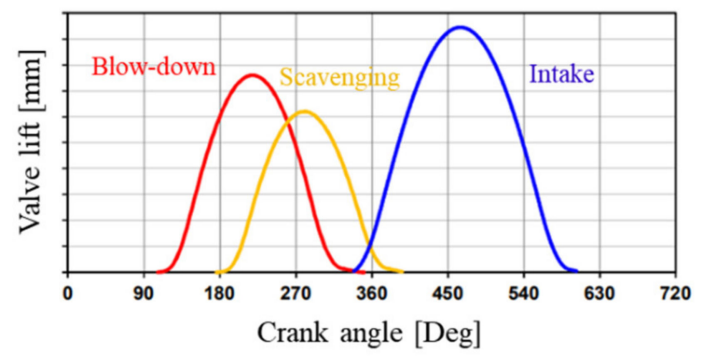

(b)

Figure 1. (a) Schematics of DEP engine configuration; (b) example of valve profile.

In this study, the effect of DEP technology is investigated with a high-efficiency gasoline engine. In contrast to previous studies that applied DEP technology to general downsizing engines, this study applies it to DHE, which is expected to be actively adopted in the future. In particular, this study more focuses on the synergetic effect between DEP and the high diluted combustion condition of EGR 30\%, which have not been investigated yet. The main components of the DEP engine are designed through GT power simulation in order to achieve engine performance targets and maximize fuel efficiency improvement. Designed DEP components are fabricated and integrated on the base engine. The prototype DEP engine is tested on the engine dynamometer. Unlike most previous studies conducted under limited test and simulation conditions, the authors try to comprehensively evaluate the effects of technology for various engine aspects, including full-load engine performance, thermal efficiency in DHE operating region, and catalyst-heating light-off time. Throughout this comprehensive investigation, this study aims to present the details of the DEP system implementation approach and to discuss its effects on a practical multi-cylinder engine. Evaluation and optimization processes are focused on the practical engineering perspective. The detailed characteristics of DEP technology, including its pros and cons, will be discussed, along with experimental results, of which will be of interest to the powertrain engineers working to develop advanced engines for higher efficiency. 


\section{Prototype Engine Development}

\subsection{Base Engine}

The base engine in this study was a prototype 2.0L I4 turbocharged gasoline direct injection (TGDI) engine developed for high-efficiency DHE project. It had a high compression ratio of 13 with a late intake valve closing strategy to realize the Miller cycle with a higher expansion ratio and a reduced effective compression ratio [17]. The engine was also equipped with a low-pressure EGR system that mitigates knocking combustion for an optimized combustion phasing. A high diluted combustion strategy with an EGR rate of up to $35 \%$ was applied, and stable combustion was ensured with high tumble ratio and twin-spark high energy ignition. The engine also had an integrated exhaust manifold (IEM) to reduce fuel enrichment for the exhaust component protection under high load conditions [27]. The integrated exhaust manifold had two exhaust ports branching into cylinders 2, 3 and 1, 4 respectively. Details of techniques and optimization strategies can be found in the author's previous work [17]. The engine in the literature is an NA engine while the basic engine in this study is a turbocharged engine, but the basic configuration technology and optimization strategy of both engines are the same. The specifications of the base engine are summarized in Table 1.

Table 1. Specifications of the Test Engine.

\begin{tabular}{cc}
\hline Items & Specifications \\
\hline Displacement & Prototype 2.0L \\
\hline Number of cylinders & I4 \\
\hline Bore & $102 \mathrm{~mm}$ \\
\hline Stroke & $13: 1$ \\
\hline Compression ratio & DOHC, dual hydraulic CVVT \\
\hline Valvetrain & Lateral-mounted GDI \\
\hline Fuel injection & Twin scroll, electronic wastegate actuated \\
\hline Turbocharger & $41 \%$ \\
\hline Maximum Power & Twin spark plug with high energy coil (120 mJ) \\
\hline Maximum thermal efficiency & SAE 5w30 \\
\hline Ignition system & IVO: 10 CA ATDC (at $0.15 \mathrm{~mm}$ lift), \\
\hline Lubricant & IVC: 90 CA ABDC (at 0.05 mm lift) \\
\hline Intake cam timing & EVO: 37 CA BBDC (at $0.15 \mathrm{~mm}$ lift), \\
\hline Exhaust cam timing & EVC ATDC (at $0.05 \mathrm{~mm}$ lift)
\end{tabular}

\subsection{Divided Exhaust Period System}

A schematic diagram of the DEP engine configuration applied in this study is shown in Figure 2. As explained in the introduction, the exhaust port configuration of a DEP engine must have an exhaust path separated into a blowdown port and a scavenging port, and each path must be connected to the corresponding exhaust valve in each cylinder. The modification of the cylinder head design was conducted, as shown in Figure 3 . The IEM design in the base engine has a separated exhaust port for cylinders 1, 4 and 2, 3 as shown in Figure 3a. This design was modified to be separated into a blow-down port and a scavenging port which are connected with exhaust valves of each cylinder, as shown in Figure 3b. In the layout shown in Figure 3b, the upper port was for the scavenging period, while the blow-down port was located below it. Except for the exhaust path layout, the rest of the features of the cylinder head design were kept unchanged to have the minimized modification and the same combustion characteristics. 


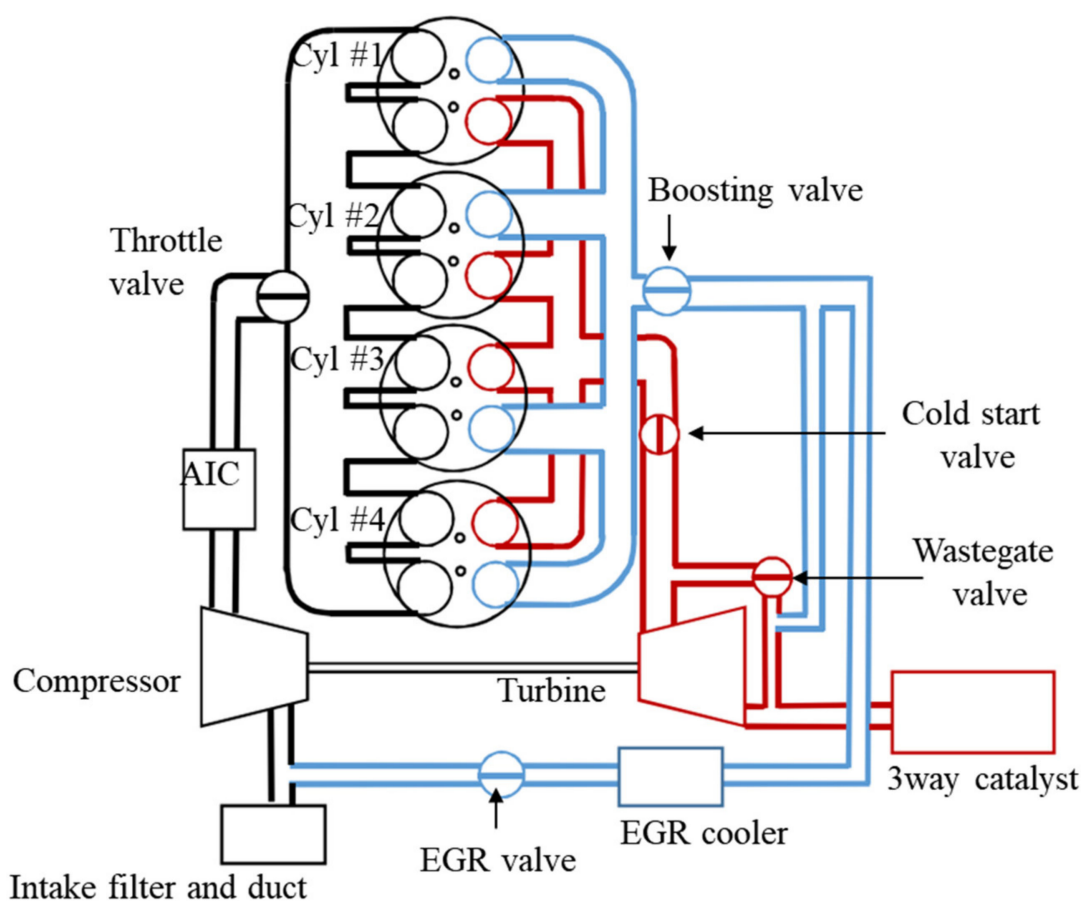

Figure 2. Schematics of developed DEP engine.

As shown in Figure 2, a wastegate valve that allows the exhaust flow to bypass the turbine was applied between the blow-down port and the turbine inlet. This valve works identically to the valve on a conventional TGDI engine. A boost valve was installed between the scavenging port and the three-way catalyst, to cut off the exhaust flow of the scavenging path and to allow more flow in the blowdown path under full load conditions where boosting may be insufficient. In Figure 3, a cold-start valve was depicted to be installed on the blow-down path. This valve was considered to block the exhaust flow in the blowdown path and to minimize heat loss to the turbocharger, with high thermal inertia during cold-start catalyst-heating operation. However, in practice, this valve was not implemented in the developed DEP engine due to the complexity of the system and the difficulty of the engine control. Instead, we evaluated the feasibility of the idea in engine tests by installing a wall plate to block the blowdown ports under simulated catalystheating operating conditions. The EGR system of the base engine was also modified. EGR is collected upstream of the catalyst in the scavenging path, as suggested in previous studies [21,22], which can provide not only lower PMEP but also burning of UHC emissions in the scavenging sourced EGR. The specifications of the EGR cooler, valve, and pipe were also re-designed to meet the requirement for the high EGR rate. After the design of each component in the DEP system has been completed, components have been fabricated and integrated with the base engine for the engine test. The development target of the test engine is summarized in Table 2. These goals were derived by considering its application to HEV. As shown in Table 2, engine power and torque performance targets were relatively modest, while the thermal efficiency target was a bit challenging. 

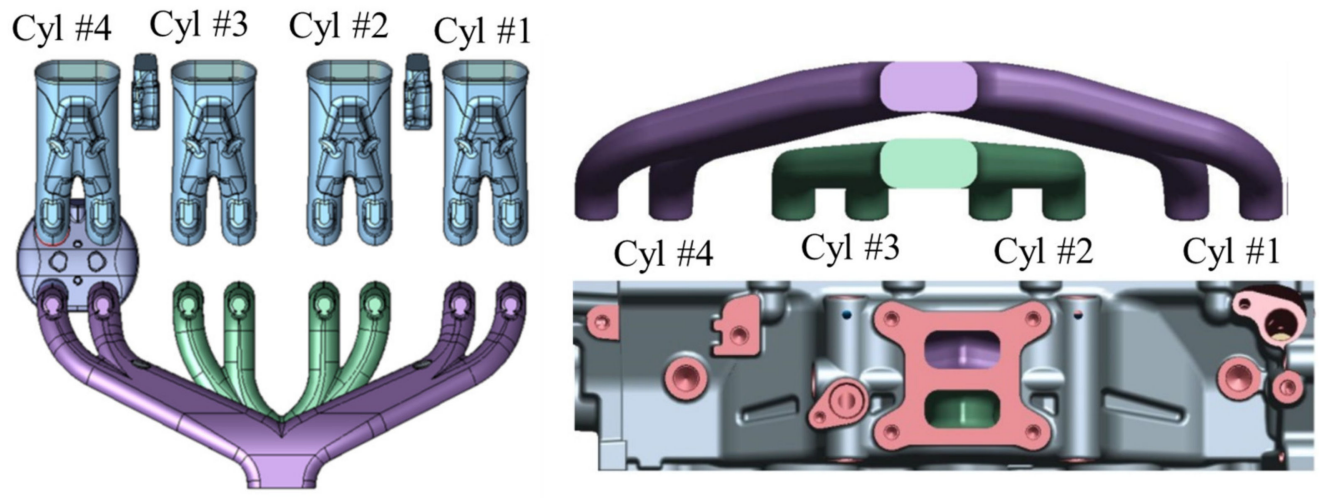

(a)
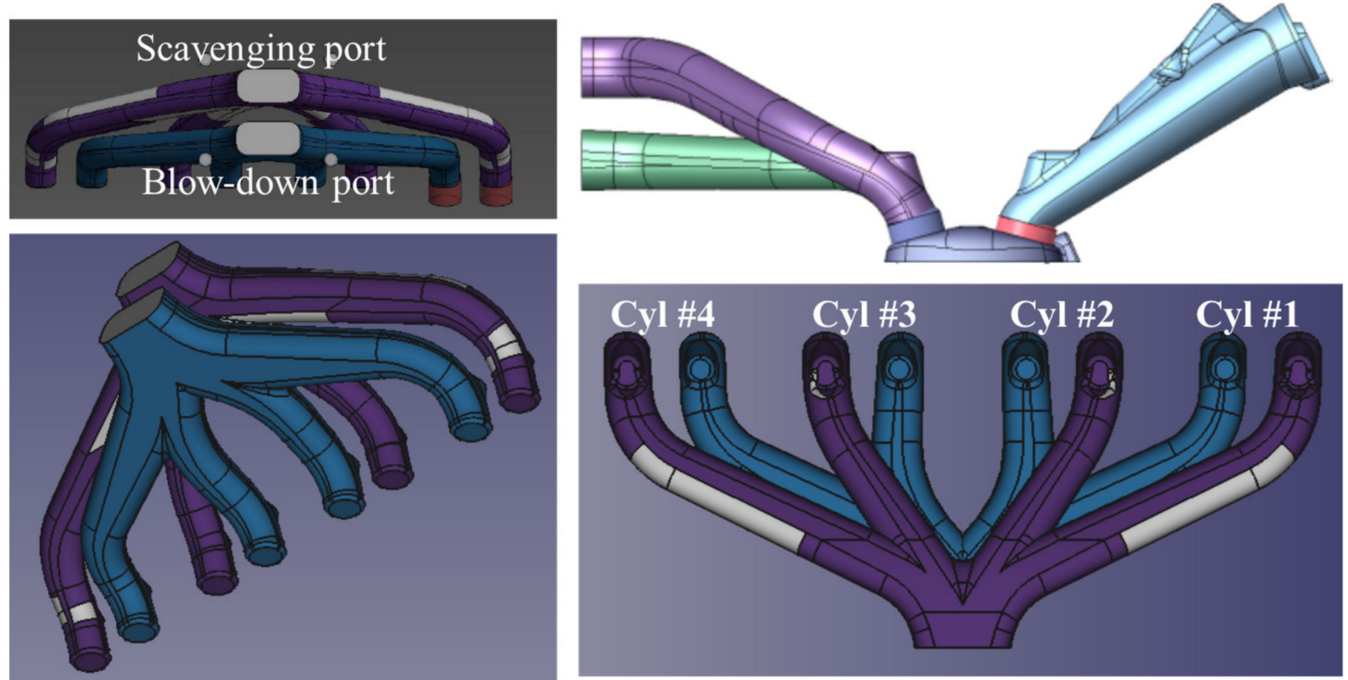

(b)

Figure 3. (a) Exhaust port configuration of the base engine; (b) IEM design for DEP.

Table 2. Development target of test engine with DEP.

\begin{tabular}{cc}
\hline Items & Target \\
\hline Maximum power & $200 \mathrm{PS}$ \\
\hline Rated rpm & $5500 \mathrm{rpm}$ \\
\hline Maximum BMEP & $18 \mathrm{bar}$ \\
\hline LET engine speed & $1500 \mathrm{rpm}$ \\
\hline Maximum thermal efficiency & $43 \%$ \\
\hline
\end{tabular}

\subsection{Parameter Design of DEP Compoenents}

\subsubsection{GT Power Model}

As introduced in the previous section, GT power simulation was performed to derive the detailed specification for the main components of the DEP engine. GT-Power has been the industry-standard engine simulation for decades. GT-Power performs 1-D simulation of the flow in the engine components. Flow passages in the engine having complex 3D geometries are simplified and modeled with 1-D flow models with predefined coefficients to reflect 3D effects of flow and heat transfer. It also has thermodynamic models and combustion models to simulate engine combustion and power stroke. In this study, engine combustion was modeled with Wiebe models based on the test result of the base engine. GT power model of the base engine model was generated based on its specifications, components geometries and engine test results. After validating the base engine model, 
the model was modified to reflect the characteristics of the DEP cylinder head. The exhaust port layout of the model was modified based on the 3-D computer-aided design (CAD) model of the DEP cylinder head. In GT power simulation, gas exchange of the engine is modeled as 1-D flow with discharge coefficients as a function of valve lift, which can be measured in a steady state flow bench. The newly fabricated DEP cylinder head was tested in a steady state flow test rig and the measured flow coefficients were updated in GT power model. Averaged coefficients representing the blowdown path and the scavenging path are calculated from the measured coefficients for each cylinder and port and applied to the GT power model. The detailed methodology of steady-state engine port flow measurements can be found in the authors' previous study [28]. Figure 4 shows the GT power model for the DEP engine utilized for optimization of design parameters which will be discussed in the following subsections.

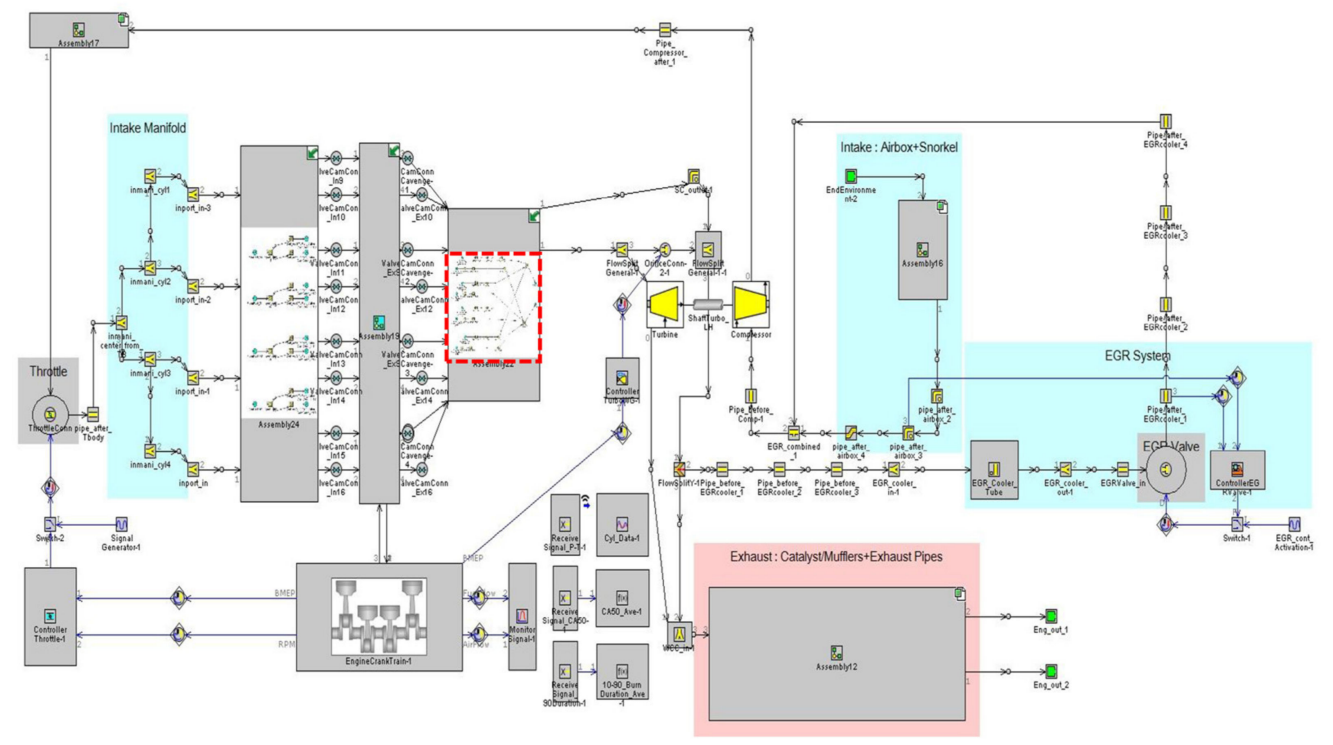

(a)

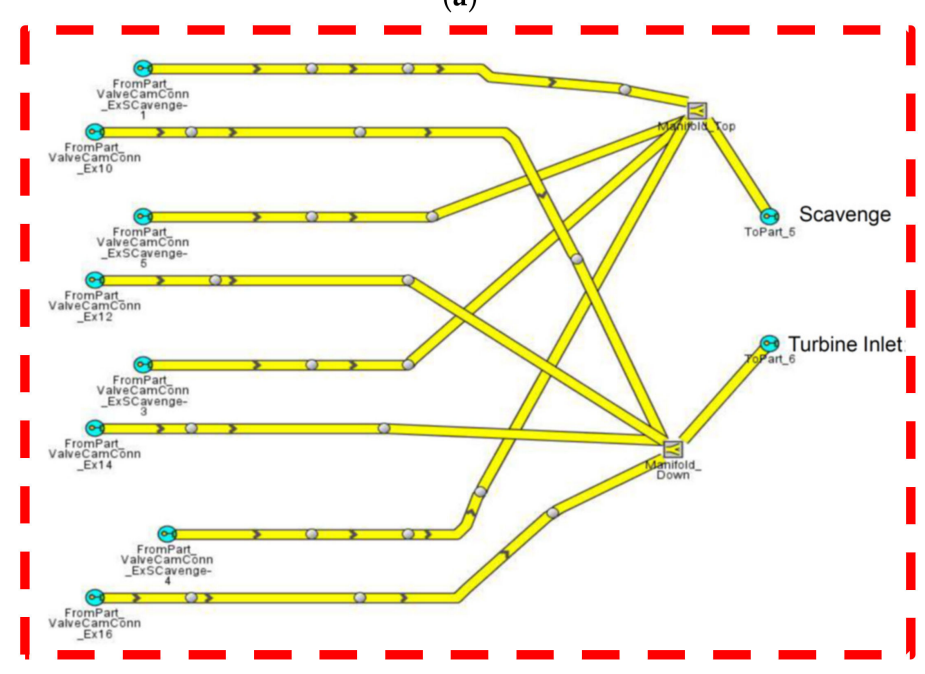

(b)

Figure 4. GT power model of the DEP engine: (a) Overall engine model; (b) exhaust configuration.

\subsubsection{Turbocharger Matching}

Proper turbocharger matching is necessary for TGDI engines to meet boosting requirements for both LET and rated power. This task is especially important in DEP engines, where exhaust enthalpy must be supplied to the turbine through a limited exhaust process. For the turbocharger matching with GT power simulation, initial exhaust cam profiles were 
derived based on the results of the author's previous studies [21-23], and turbocharger matching was conducted with those profiles. Four different turbocharger candidates, combinations of 'off-the-shelf' compressors and turbines was assessed. Figure 5 shows the result of the GT power simulation. A brief overview of turbocharger specifications can be seen in the legend in Figure 5. The turbochargers simulated have different combinations of compressor wheel diameter (Dc), trim ratio (TR), and turbine wheel diameter (Dt) specifications. In detail, turbocharger 1 has the smallest compressor wheel size and turbine wheel among these specimens. Turbos 2 and 3 have the larger compressor and turbine wheels, while turbocharger 3 has the smaller TR. Lastly, turbocharger 4 has a medium-sized compressor turbine wheel compared to others. Compressor wheel diameter and trim ratio are parameters related to compressor performance. In general, larger compressor wheels and higher trim ratios increase compressor efficiency at higher mass flow conditions and choke line margins, and conversely, these deteriorate the surge line margin and compressor efficiency at smaller mass flow conditions. In addition, the larger diameter of the compressor increases the rotational inertia of the compressor may increase delaying the transient response. The turbine wheel diameter is the most critical parameter for the performance of the turbine. Large turbine wheels increase the turbine efficiency and reduce the upstream turbine pressure (P3) at higher mass flow rate conditions, but it may not be sufficient to provide necessary the turbine work for the boost under low mass flow conditions and transient dynamic operation conditions. Therefore, these turbocharger parameters need to be optimized in consideration of engine specifications and operating conditions.

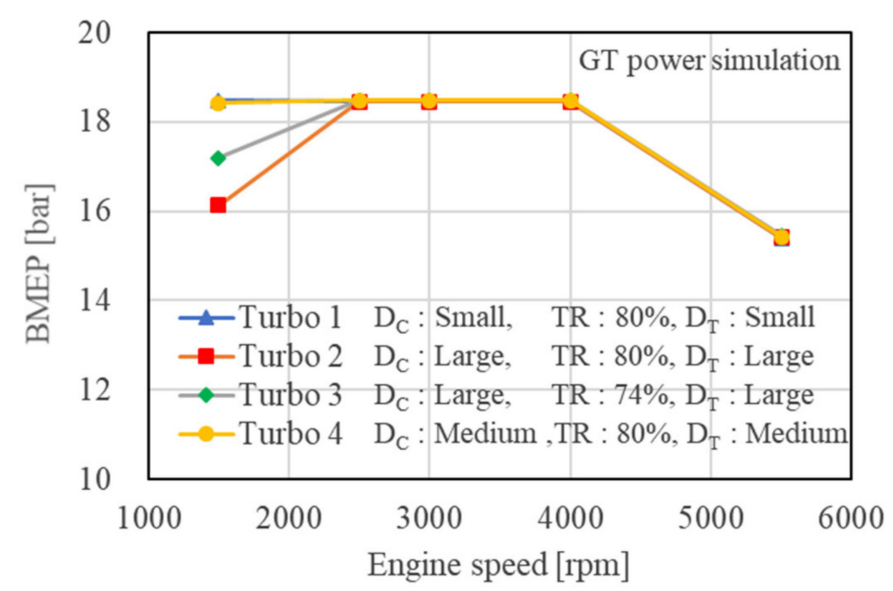

(a)

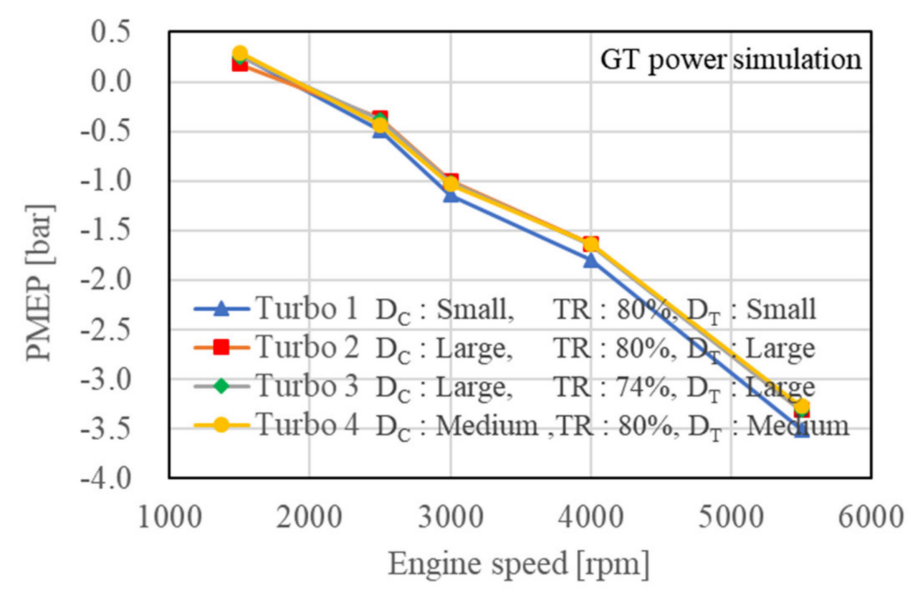

(b)

Figure 5. GT power simulation result for full load engine performance: (a) Engine torque; (b) PMEP. 
As can be seen in Figure 5, results of GT Power simulation showed that Turbos 1 and 4 were found to meet the required boost performance, while Turbos 2 and 3 having higher inertia of compressor missed goals for LET. In addition, Turbo 4 was found to have reduced pumping loss due to favorable turbine and compressor matching compared to Turbo 1 . As a result, Turbo 4 was selected as the best combination of 'off-the-shelf' specifications to match the development target and was used for further numerical simulations and engine testing. The performance maps of the selected turbocharger are shown in Figure 6.

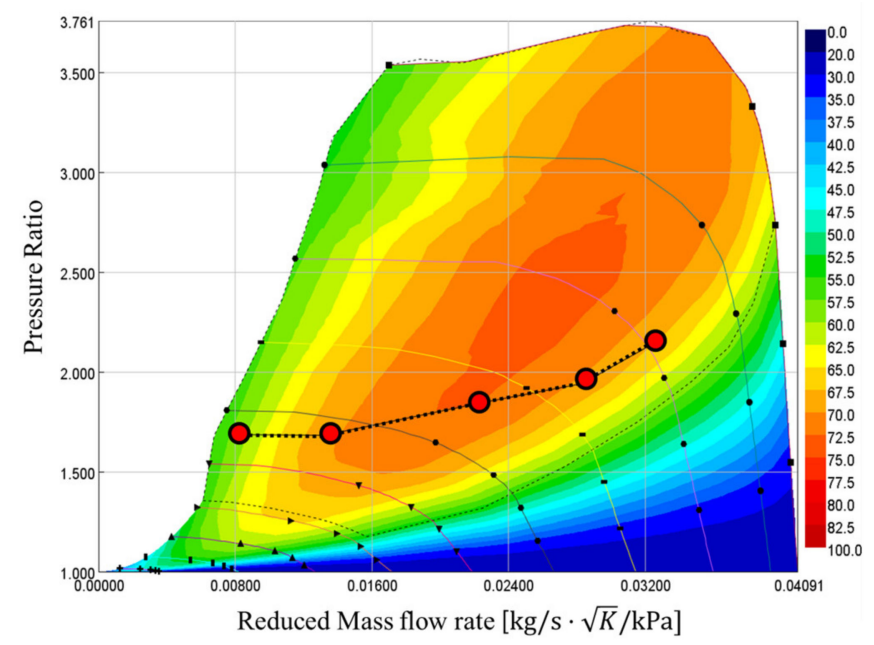

(a)

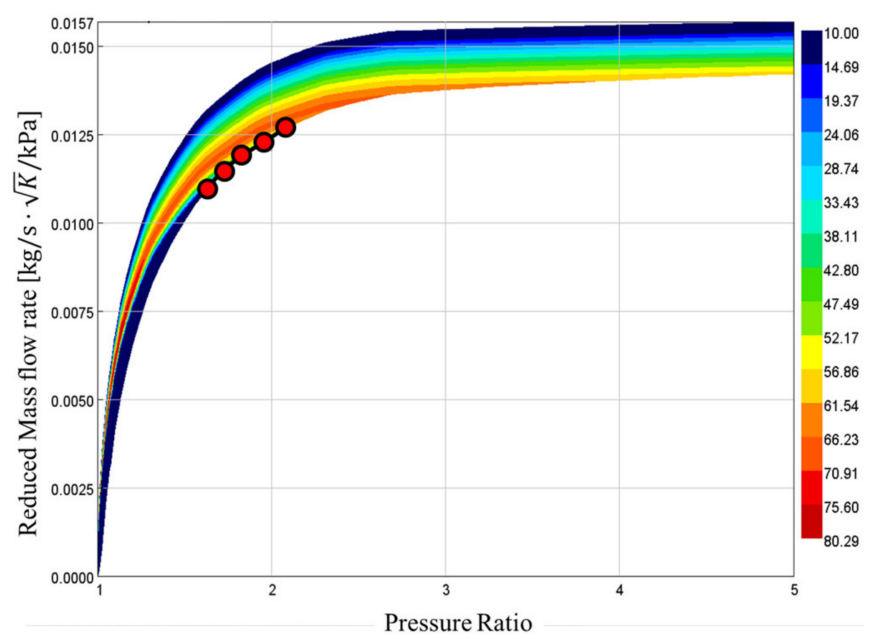

(b)

Figure 6. Performance of selected turbocharger: (a) Compressor map; (b) turbine map.

\subsubsection{Exhaust Cam Profile}

From the principle of a DEP engine described in the Introduction, it is clear that exhaust valve phasing and duration have significant impacts on the performance and fuel consumption of the engine. Iterative GT power simulations were performed to optimize the exhaust cam profile. Three candidates for valve durations were defined initially for both the blowdown and scavenge periods based on the previous experience [21-23], and the corresponding valve lift profiles could be calculated as the maximum allowable lift considering kinematic restrictions to prevent irregular valve behaviors, such as jumping and bouncing. Determined initial exhaust valve lift and duration to be assessed are shown 
in Figure 7. The derived profiles were evaluated by 1-D simulation using the initial separation angle provided based on the previous study. Simulation results showed that the longer blow-down period with higher valve lift can be beneficial to provide desired turbine work and improved volumetric efficiency, especially at higher engine speeds. However, longer blow-down periods can interfere with scavenging period. This yields a scavenging period to be retarded or to be overlapped, while both can adversely affect the performance of the engine. As the overlap of blowdown and scavenging periods increases, the exhaust enthalpy supplied to the turbine can be reduced. Conversely, if the scavenging phase is retarded, it may overlap the intake cam and deteriorate engine startability. Similarly, adjusting the scavenge period valve profile must also account for non-monotonic effects on engine performance. Considering the GT power simulation results and development constraints, the median values of the valve profiles, as shown in Figure 7, were selected.

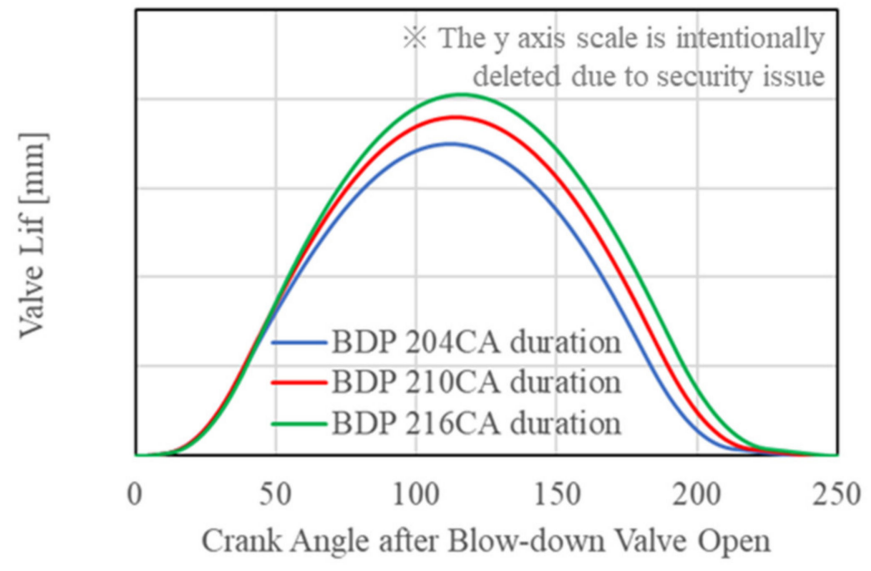

(a)

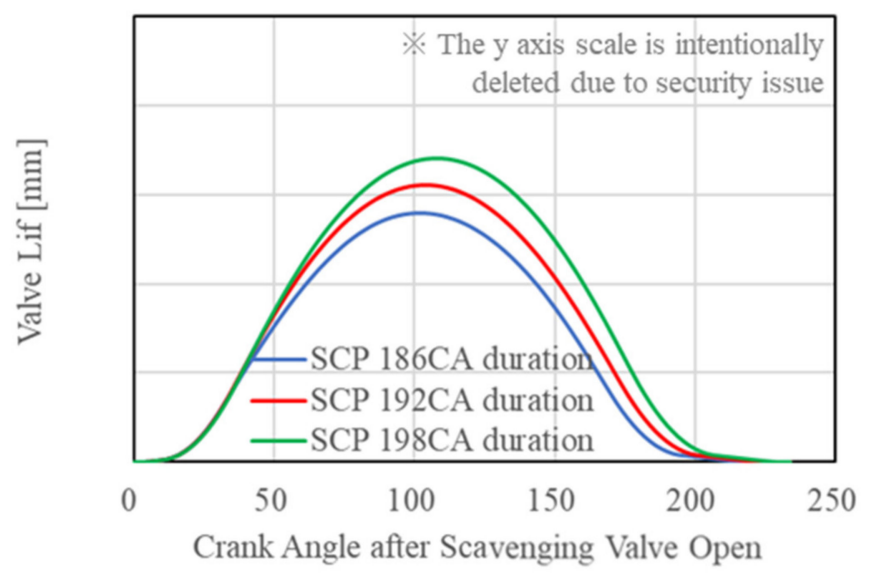

(b)

Figure 7. Initial cam profiles: (a) Blow-down period; (b) scavenging period.

Optimization of the separation angle was performed again through GT power simulation, using the selected blowdown and scavenging valve profiles. The separation angle is defined as the crank angle period between the maximum lift timing of blowdown and scavenging valves. Figure 8 shows the results of the GT power simulation for different separation angles. The study was performed vs. cam retard angle, since the engine will utilize the base engine cam phaser. Simulations were performed for separation angles in the range of $58-66 \mathrm{CA}$, derived based on the previous studies. From the simulation results, it could be seen that the optimal separation angle varies for the engine conditions. 
The lowest plumping loss and brake specific fuel consumption (BSFC) were found with smaller separation angle under the condition of $2000 \mathrm{rpm}$ and 8 bar BMEP, while larger separation angle was optimal under $2500 \mathrm{rpm}$ and 14 bar condition. In both conditions, differences were relatively small, as shown in Figure 8. In this study, the intermediate value was selected for the further simulation and engine test among the separation angles shown in Figure 8.
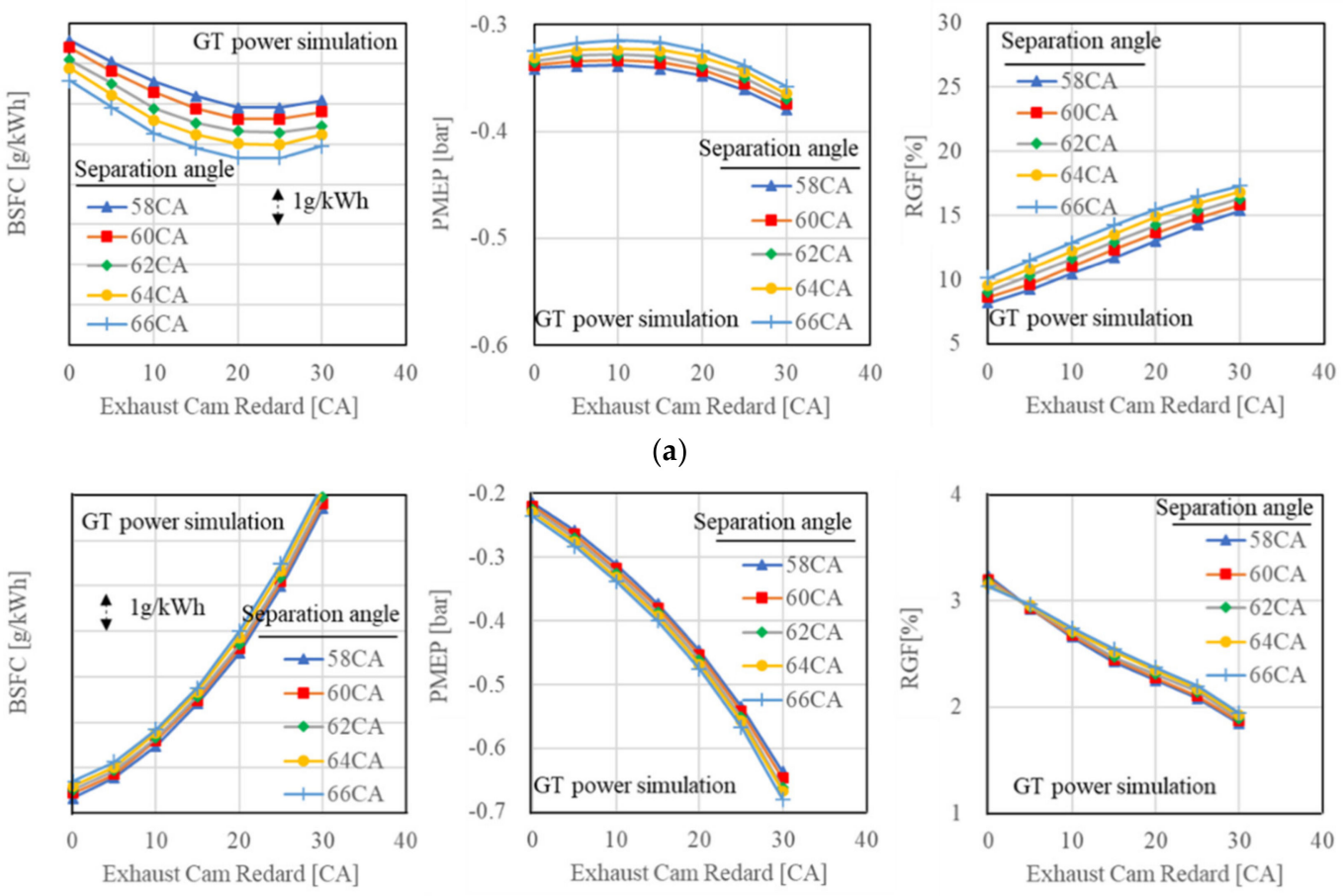

(b)

Figure 8. GT power simulation result: (a) BSFC, PMEP and RGF at $2000 \mathrm{rpm}$ BMEP 8 bar condition; (b) BSFC, PMEP and RGF at 2500 rpm BMEP 14 bar condition.

\subsubsection{Design of Other Components}

Design of other components in the DEP engine, such as a waste valve, a boost valve, and an EGR system, was also carried out through GT power simulation. For the waste valve, smaller valve sizes provide better controllability of the turbine work, but also increase energy loss due to pressure loss near the wastegate. Therefore, it is designed to have the largest diameter controllable by an electrical actuator considering the control precision, while being able to supply required boosting to achieve the LET target at $1500 \mathrm{rpm}$. The size of the boost valve is a trade-off between pumping loss and the available maximum boost. If the diameter is small, it is advantageous to secure the required boost level, while it unfavorably increases pumping loss. The optimized size of around $30 \mathrm{~mm}$ was decided by the GT power simulations under various engine operating conditions. For the EGR system, specifications of the EGR valve, cooler, and pipes were designed in consideration of the high EGR flow rate as applied to the base engine. In particular, since the UHC contents in the scavenging-sourced EGR is high, EGR cooler capacity was determined to have a sufficient safety margin, considering severe fouling in the worst case.

\subsubsection{Detail Design and Prototyping}

After the optimization of design parameters of the DEP components, a detailed design of the system was carried out. Figure 9 shows a 3D CAD model of the turbocharger assembly, one of the most requested DEP components for design consideration. The detailed design of the system was carried out considering the integration of various 
components including turbocharger, valves and housing, electric motors and mechanical linkages, and their relative placement with other engine parts.

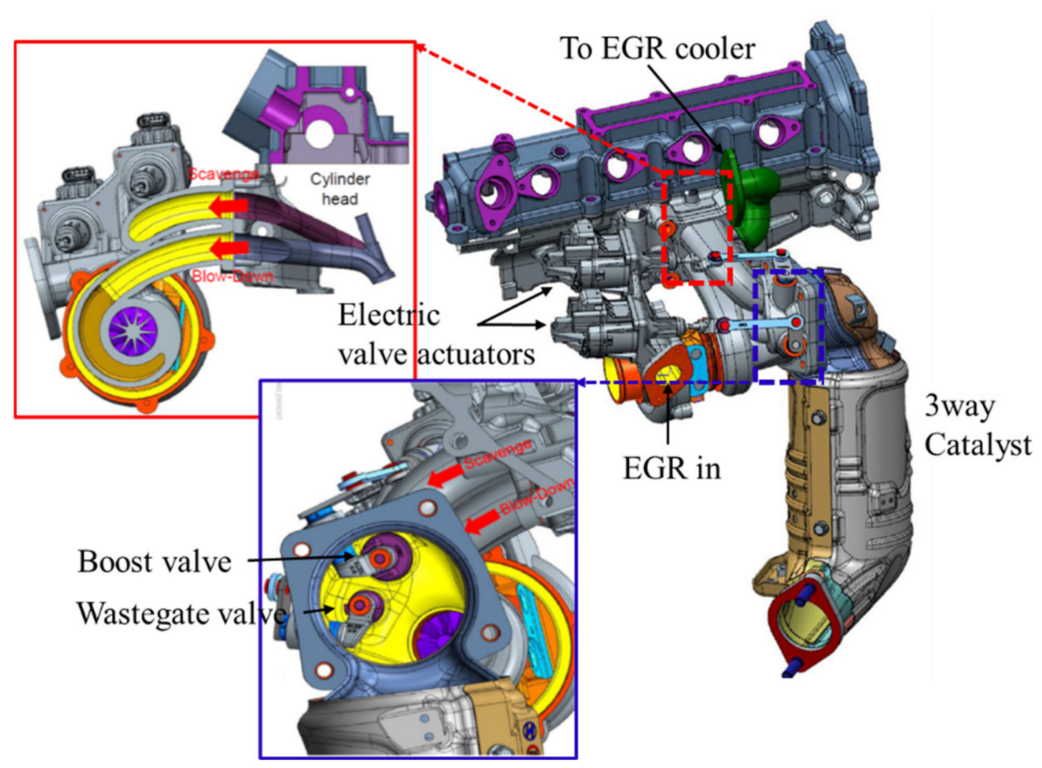

Figure 9. Turbocharger assembly design.

After the detailed design of each component, fabrication of components was carried out. Most of the main components, such as the cylinder head, exhaust camshaft, turbocharger, wastegate, boost valve, and EGR system, were newly fabricated. The fabrication of the cylinder head and exhaust camshaft was carried out by Hyundai Motor Company, the EGR system was produced by the BorgWarner Emission Systems and prototyping of other components was performed by the BorgWarner Turbo Systems. For the control of DEP components, a slave engine control unit (ECU), where the rapid prototyping control logic was flashed, was used along with the master ECU, which was used for the base engine. Together with integrated DEP components, the engine's lubrication system is updated with a variable oil pump to evaluate the lowest BSFC levels through the comprehensive application of engine technology. The effectiveness of DEP alone can be assessed by compensating for differences in friction losses.

\section{Engine Test}

\subsection{Test Methodology}

The tests were conducted on the engine test bench with an AC dynamometer $(250 \mathrm{~kW}$, Dynas3 LI250 manufactured by Horiba Automotive, Kyoto, Japan). A torque meter was installed on the dynamometer to measure the engine torque with an accuracy higher than 99.5\%. A Coriolis flowmeter (AVL 735S manufactured by AVL, Graz, Austria), which can measure fuel flow ranging from 0.2 to $125 \mathrm{~kg} / \mathrm{h}$ with a measurement uncertainty lower than $0.12 \%$, was used for fuel consumption measurement. Combustion characteristic indices, such as COV (coefficient of variation) of gIMEP (gross indicated mean effective pressure), combustion speed, and combustion phasing, were calculated through a combustion analyzer (INDISMART manufactured by AVL, Graz, Austria), which uses the in-cylinder pressure signal measured by piezoelectric pressure transducers (6056A manufactured by Kistler, Winterthur, Switzerland) with 0.1 crank angle (CA) resolution. Moreover, the polytropic processes, with a coefficient of 1.35 for compression stroke and 1.3 for expansion stroke, were used for zero level correction and heat release rate calculation. TDC was thermodynamically found by the motoring condition at $2000 \mathrm{rpm}$ with a loss angle assumption of 0.7 CA. The exhaust emissions and EGR rate were analyzed by an exhaust gas analyzer (MEXA 9100 EGR manufactured by Horiba Automotive, Kyoto, Japan). The linearity and repeatability of the exhaust gas analyzer are within $2 \%$. During the engine 
test, conditioned air at standard temperature and humidity was supplied to the intake duct of the engine. Coolant outlet temperature was controlled to be $90^{\circ} \mathrm{C}$ and the intercooler (AIC) temperature was set to be $35^{\circ} \mathrm{C}$. RON92 market gasoline was used as a test fuel.

For the optimization of engine control parameters in part load and full load engine tests, more than 3000 test points were examined to optimize engine control parameters, such as the intake and the exhaust cam timings and the EGR rate, in order to have the lowest BSFC while satisfying development constraints as follows. COV of gIMEP was limited to $2.5 \%$ as an index of combustion stability. The maximum allowable exhaust temperature was $950^{\circ} \mathrm{C}$ for both at the catalyst and upstream of the turbine. If the exhaust temperature exceeds the allowable limit, fuel enrichment was applied up to $\lambda=0.85$, while the stoichiometric air:fuel ratio was applied under general conditions. Both intake and exhaust cam position targets were limited to have a smooth gradient of phasing change for engine speed and load variation, considering the dynamic response of the hydraulic cam phasers. Spark timing was set to be MBT or knock limit, while additional retardation was applied if the maximum in-cylinder pressure exceeds the allowable limit. Table 3 shows a summary of test parameters and Figure 10 shows the pictures of the prototype DEP engine and engine test bench.

Table 3. Test condition and parameters.

\begin{tabular}{cc}
\hline Intake cam phasing & $0-70$ CA advance \\
\hline Exhaust cam phasing & $0-50$ CA retard \\
\hline Ignition timing & MBT or knock limit \\
\hline EGR & $0-30 \%$ \\
\hline Lambda & $0.85-1$ \\
\hline Injection timing (1st) & $320-250$ CA BTDC \\
\hline Injection pressure & $80-200$ bar \\
\hline Number of injection & up to 2 (double injection) \\
\hline Engine load (BMEP) & $1000-5500$ rpm \\
\hline Engine speed & $90{ }^{\circ} \mathrm{C}$ \\
\hline Coolant temperature & $\sim 3000$ \\
\hline Number of test point
\end{tabular}

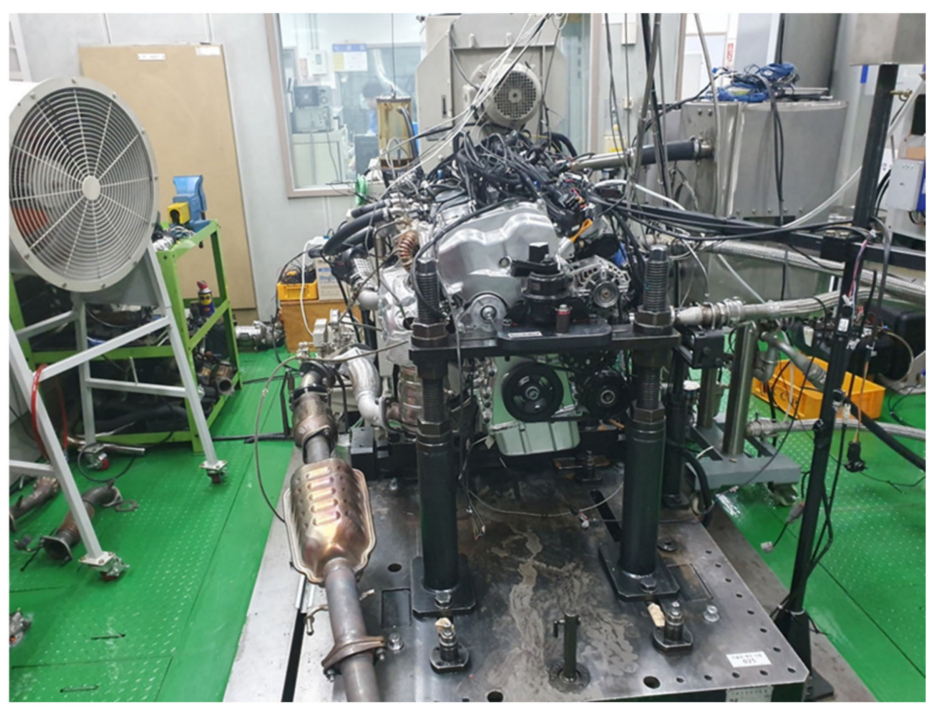

Figure 10. Test engine and test bench. 


\subsection{Engine Test Result}

\subsubsection{Full Load Performance}

Figure 11a shows the result of full load engine performance test at engine speed from 1500 to $5500 \mathrm{rpm}$. The development targets of the maximum torque and power could be achieved with the DEP implementation. The maximum torque exceeded 18 bar brake mean effective pressure (BMEP) at $1500 \mathrm{rpm}$ and the maximum output of $200 \mathrm{PS}$ was achieved. The full load performance of the DEP engine is regarded to have sufficient performance as an DHE. In particular, considering that the tested engine is a TGDI engine with a high compression ratio of 13, the full load performance shown in Figure 11 seems reasonable.

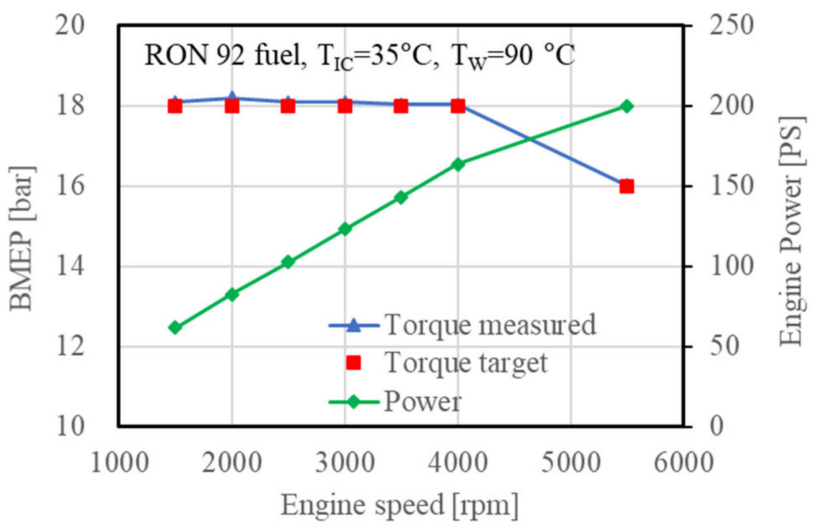

(a)

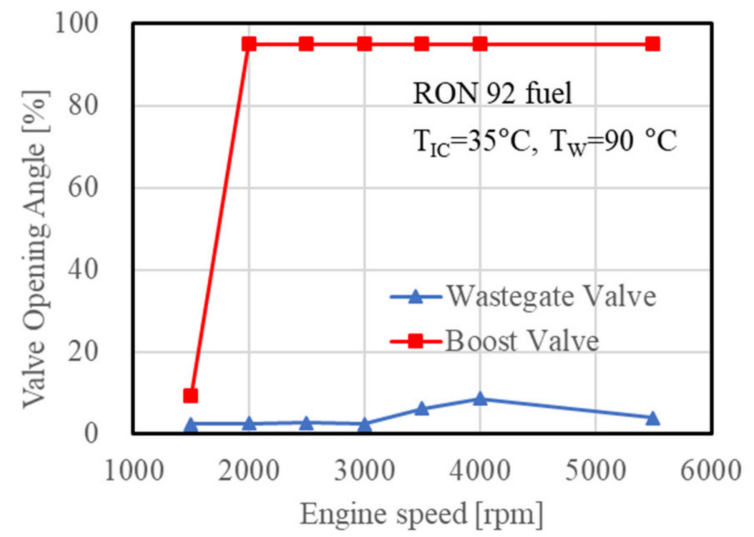

(b)

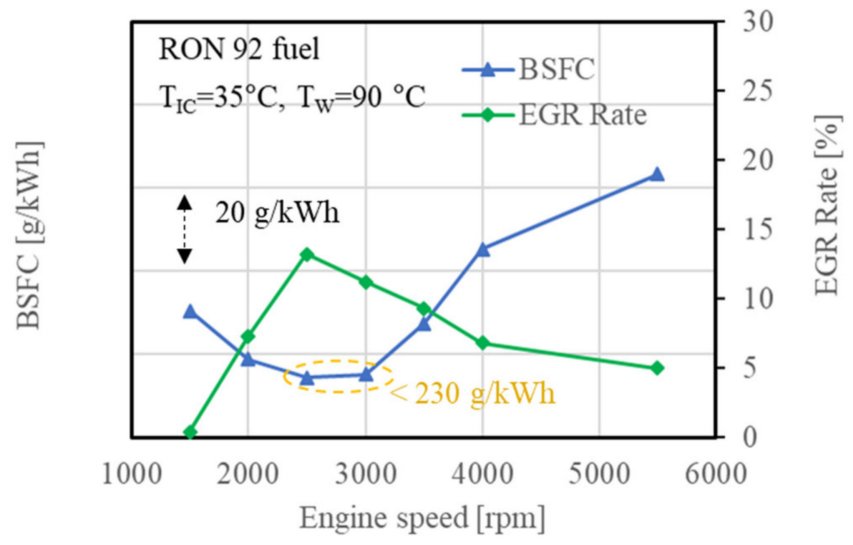

(c)

Figure 11. (a) Full load performance; (b) exhaust control valves operation; (c) BSFC and EGR rate. 
The required peak boosting level cannot be achieved without closing the boost valve and shutting off the exhaust flow in the scavenging path at $1500 \mathrm{rpm}$, as shown in Figure 11b. However, from $2000 \mathrm{rpm}$, the target performance could be achieved with the boost valve fully open. In particular, it was possible to apply a small EGR from $2000 \mathrm{rpm}$ and full load efficiency could be greatly improved. If LET does not need to occur at $1500 \mathrm{rpm}$, considering that it is developed for the HEV dedicated engine, the boost valve can be omitted in the configuration. This will be able to reduce the cost and complexity of the system, as well as create a slight improvement in turbine efficiency through the simplification of the turbine housing geometry. The maximum boost pressure was about 2 bar absolute, and the maximum speed of the turbocharger was 180,000 rpm within the allowable range.

\subsubsection{Part Load Efficiency}

Figure 12a shows a comparison of part-load BSFC under various load conditions at $2000 \mathrm{rpm}$. The engine was operated with stoichiometric conditions with EGR. As explained in Section 2.2, the DEP engine was equipped with a variable oil pump system while the conventional oil pump was used in the base engine; therefore, the DEP engine showed reduced enhanced frictional loss as shown in Figure 12. To show the effect of DEP implementation independent of the lubrication system, the frictional mean effective pressure (FMEP) compensated BSFC of the base engine is depicted, along with the BSFC curves of the DEP engine and the base engine. In Figure 12, it is confirmed that the high efficiency under $200 \mathrm{~g} / \mathrm{kWh}$ was possible through the combination of high-efficiency gasoline engine combustion technologies, advanced lubrication system, and DEP implementation. The improvement in BSFC was approximately $3 \%$ at the lowest BSFC point. The specification and geometry of the combustion chamber were the same for the base engine and the DEP engine, and there was no clear different tendency in the combustion characteristics in the test results. The improvement of BSFC appears to be mainly due to the reduction of pumping losses by the implementation of DEP. Figure $12 \mathrm{~b}$ shows the comparison of PMEP for the base engine and DEP engine. It can be confirmed that the pumping loss of the DEP engine was significantly improved compared to the base engine in the engine load higher than BMEP 8 bar. Boosting is required to supply EGR under these conditions, and as the EGR rate and the corresponding turbine work increase, the turbine upstream pressure (P3) increases. Therefore, in conventional TGDI engines, PMEP deteriorates at a high EGR rate under these conditions. In contrast, the DEP engine showed positive PEMP in these conditions despite the high EGR rate.

As described above, the pressure upstream of the turbine (P3) increases as the turbine work increases to supply EGR in boosting conditions. This trend can be seen in Figure 13a for both the base engine and the DEP engine. As a result, pumping loss increases as the EGR rate increases in the base engine, while the opposite trend is observed in the DEP engine. In the DEP engine, the scavenging port pressure is not increased with the increase of the turbine work, because the scavenging port is separated from the turbine. Additionally, since EGR is collected from the scavenging port, as the EGR flow rate increases, the pressure at the scavenging port and the in-cylinder pressure at the EVC timing decrease. This characteristic is that PMEP improves as the EGR ratio increases, as shown in Figure 13b. The synergistic effect of high diluted combustion and DEP technology can also be seen in Figure 13c. In addition, in Figure 13c, it can be seen that there is no significant difference in BSFC between the two engines at $2000 \mathrm{rpm}, 10$ bar when the EGR rate is zero. However, as the EGR rate increases, BSFC of the DEP engine becomes lower compared to the base engine due to a significant reduction in pumping losses. 


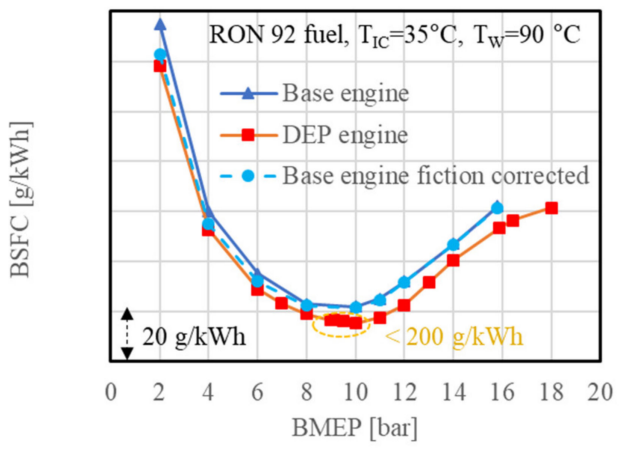

(a)

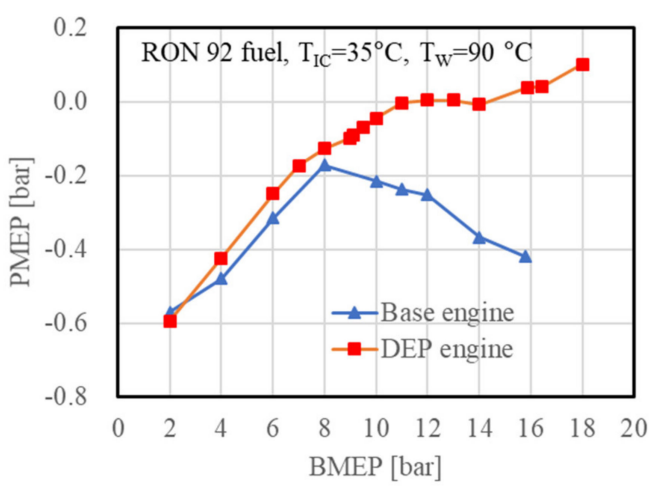

(b)

Figure 12. Part load characteristics comparison (a) BSFC (b) PMEP.

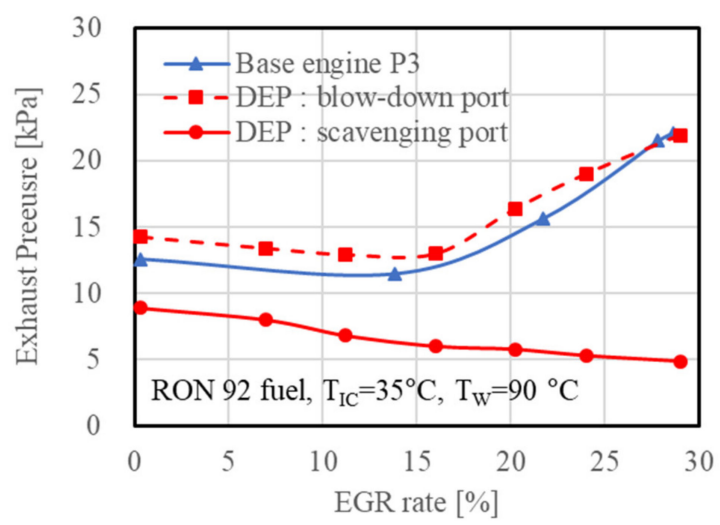

(a)

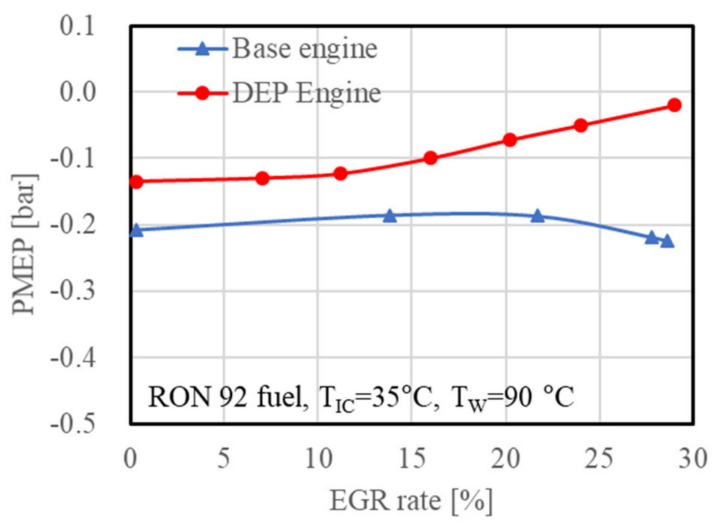

(b)

Figure 13. Cont. 


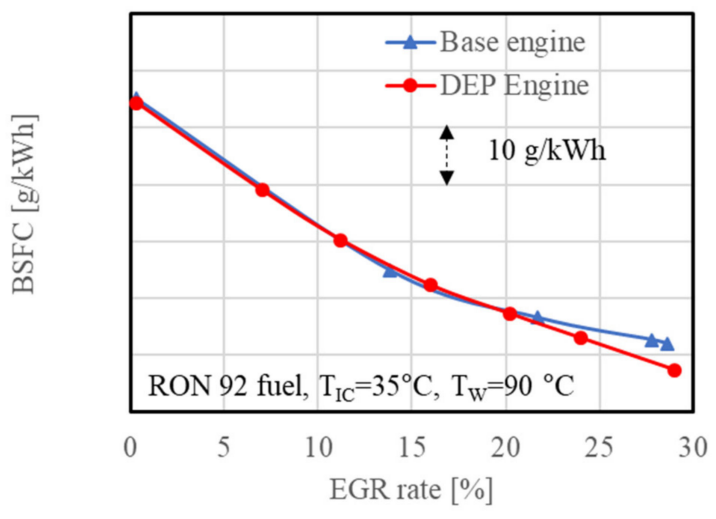

(c)

Figure 13. Synergistic effect between DEP and high diluted combustion: (a) Exhaust pressure; (b) PMEP; (c) BSFC.

\subsubsection{Engine Characteristic Maps}

Figure 14a shows the brake thermal efficiency map of the DEP engine with optimized engine operation parameters. The star symbol indicates the maximum brake thermal efficiency (BTE) point at which, the BTE of $42.5 \%$ could be achieved. In addition, a wide sweet spot area could be realized with higher thermal efficiency of over $40 \%$ under a wide engine speed range of 1200 to $3000 \mathrm{rpm}$, and load conditions of BMEP 6 to 14 bar. In particular, it is noteworthy that the high thermal efficiency could be achieved with a combination of cost-effective and well-verified technologies rather than adopting high-efficiency engine technologies requiring tricky combustion control or expensive additional system.

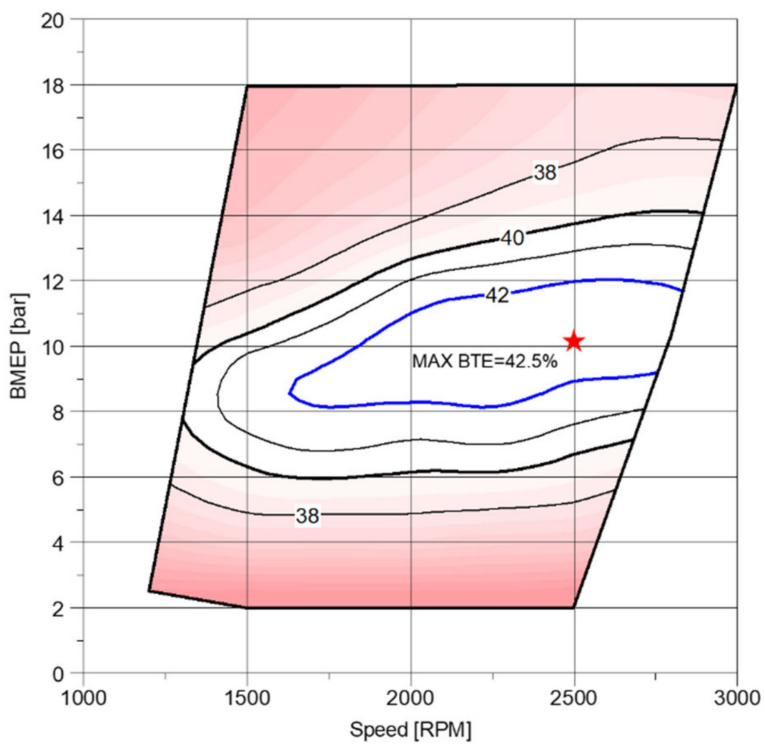

(a)

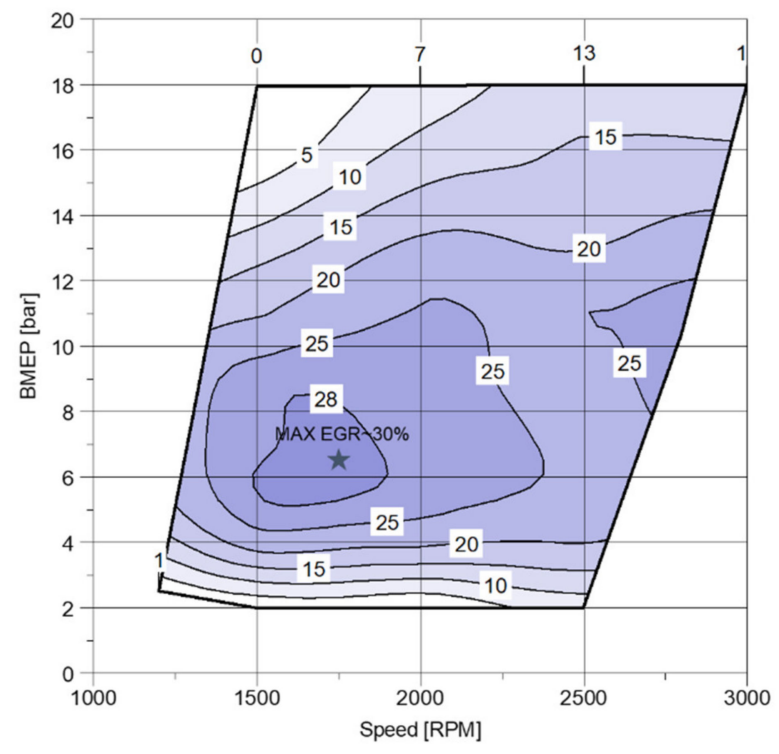

(b)

Figure 14. (a) Brake thermal efficiency map; (b) EGR rate map.

Figure $14 \mathrm{~b}$ shows the EGR rate applied in this study. High EGR of up to $30 \%$ was applied to improve thermal efficiency. In order to realize stable combustion under such highly diluted combustion conditions, high tumble and twin spark plugs were applied as suggested in the previous study [17]. As a result, stable combustion could be archived within $2.5 \%$ of COV of IMEP in all engine operating conditions even with high EGR rate of $30 \%$. 
Figure 15 shows the pressure at the blowdown port and scavenging port. As shown in Figure 15a, in the blowdown port, the pressure increases significantly as the engine speed and load increase. This pressure exacerbates the pumping losses in conventional TGDI engines. However, as shown in Figure 15b, the scavenging port shows significantly lower pressure compared to the blow-down port. Figure 16 shows the PMEP of the DEP engine. It can be seen that positive PMEP occurs in a very wide area compared to conventional TGDI engines. This made it possible to improve the efficiency of the engine despite similar combustion characteristics.

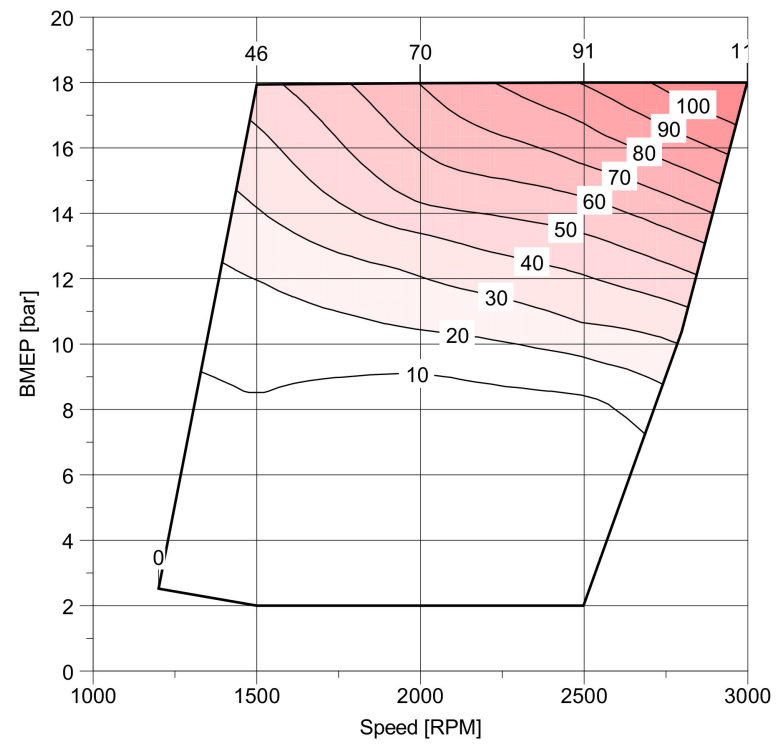

(a)

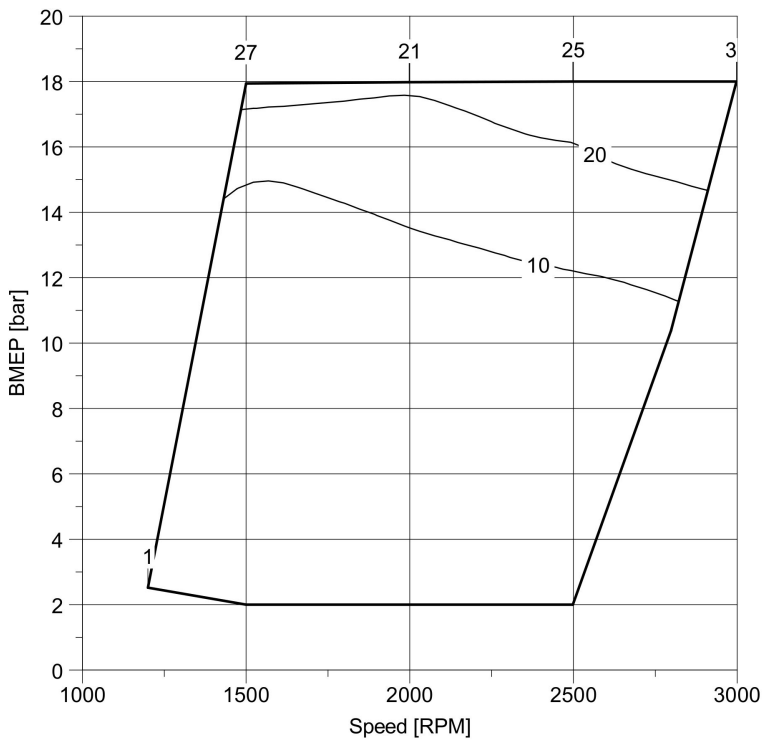

(b)

Figure 15. (a) Blow-down port pressures map; (b) scavenging port pressures map.

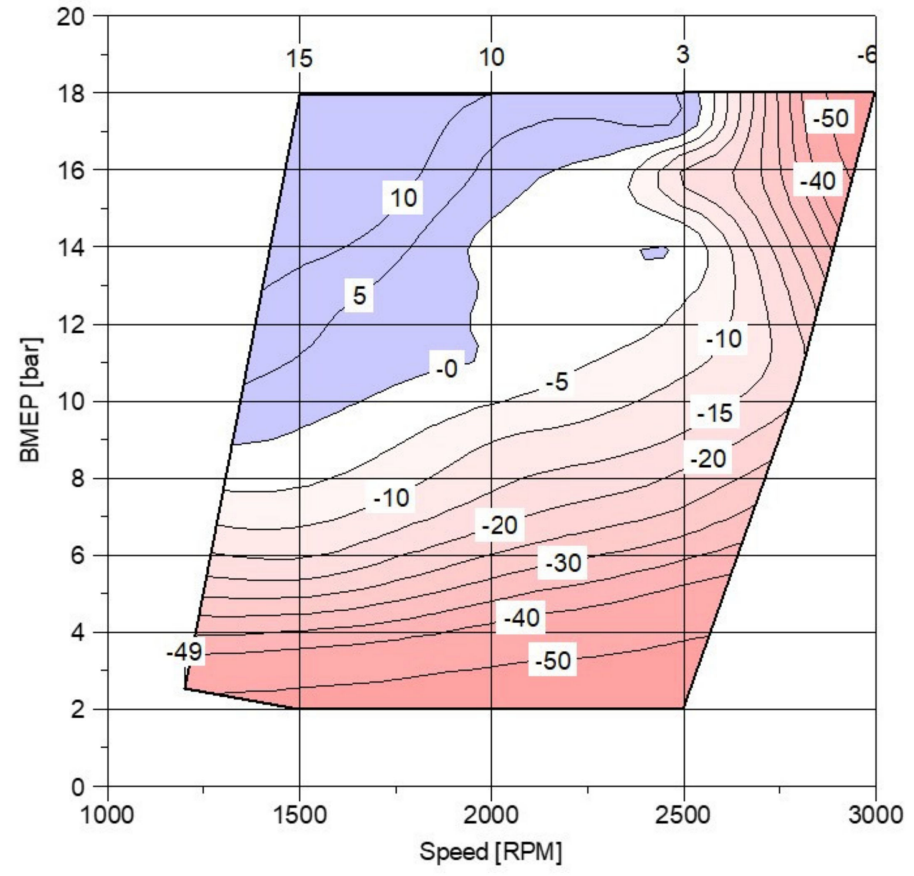

Figure 16. PMEP map. 


\subsubsection{Light-Off Time Improvement}

As discussed in the previous Section 2.2, the DEP engine can have an advantage in catalyst light-off time, because the engine can be started with the path to the turbocharger blocked by a cold-start valve $[18,23]$. In this study, the realistic cold-start valve could not be implemented; however, the feasibility of the idea was evaluated with the wall plate under the simulated catalyst-heating operation conditions. The test condition was the cold idle condition at $1520 \mathrm{rpm}$. The engine was motored shortly and then fired with the pre-set parameters as in the practical catalyst-heating operation, such as intake manifold pressure, cam timings, ignition timing, and injection strategy.

Figure 17 confirms that faster light-off time can be achieved in the DEP engine by blocking the blowdown exhaust flow and bypassing the turbine with higher thermal capacity. However, improved light-off time was not at the level of NA engines, which has a $30-40 \%$ shorter light-off time compared to TGDI engine. It is believed that the scavenging port also has a higher heat capacity than the exhaust manifold of an NA engine due to attached parts such as valves and turbine housing. Through this study, the feasibility of reducing the light-off time was confirmed, and it is thought that further improvement can be achieved through additional optimization of the exhaust system.

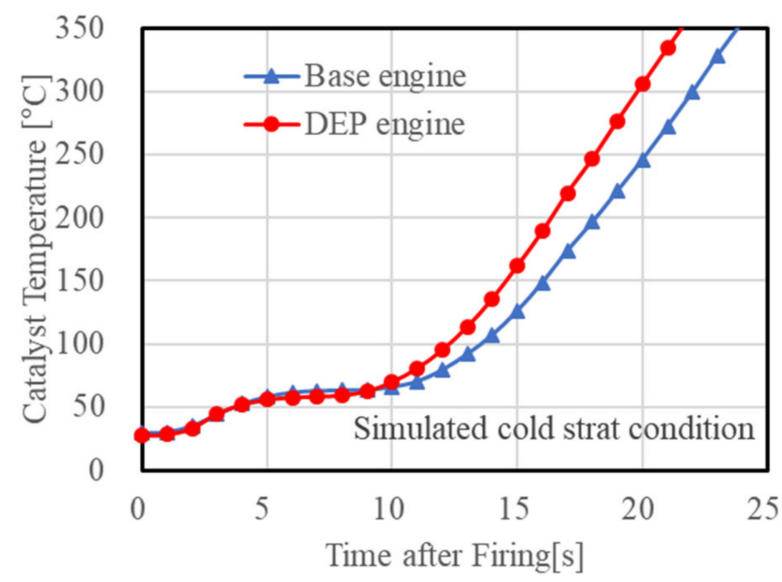

(a)

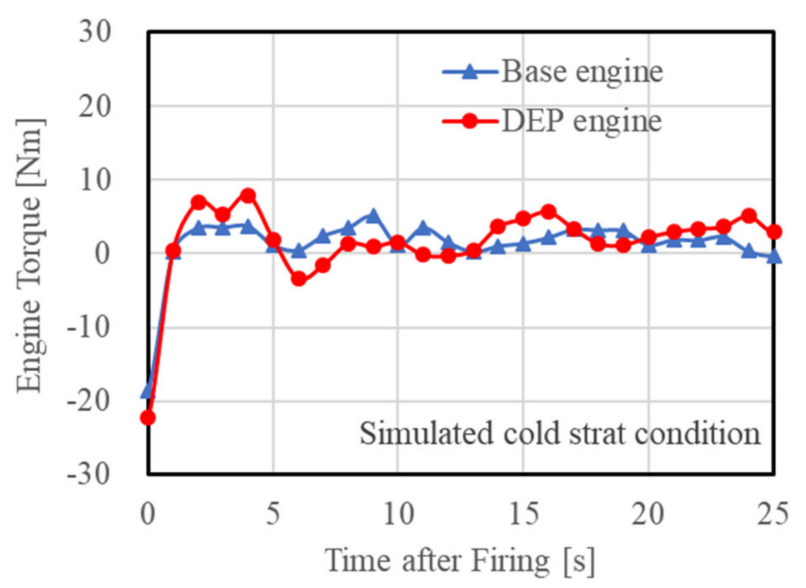

(b)

Figure 17. Light-off time reduction: (a) Comparison of light-off time: (b) engine torque under simulated cold-start catalyst-heating operation.

\section{Discussion on Technical Barriers}

In this study, the DEP engine was identified to be an improved way of coupling a turbocharger to an engine having high potential for improved efficiency and emissions 
with the affordable cost increase. However, through this study, it was possible to point out the following shortcomings that could become obstacles to future development and mass production. At first, the increase in system complexity can be pointed out as already pointed out in an early study [18]. If the system is configured, as shown in Figure 2, to take full advantage of DEP, the additional components and increased system complexity compared to traditional TGDI engines can lead to increased cost and controllability requirement. Even if the cold-start valve and boosting valve can be omitted from the configuration and the number of valves and actuators is kept at the same as in a conventional engine, the design and manufacturing difficulty of the exhaust port and turbocharger housing can be high. In addition, unfavorable system modularity can be also pointed out. DEP engines require a unique cylinder head specification which cannot be shared with other engine concepts, thus DEP engines appear to be a disadvantage in modularity and simplicity requirements being considered in engine lineups following the current electrification trend.

However, these obstacles do not appear to be very critical to the level that it is impossible to deploy into the market. In particular, as confirmed in this study, the DEP technology has a synergistic effect with the high diluted combustion technology, which is expected to become more important in the future, so it is judged to be a technology worth considering for implementation in DHE in the future.

\section{Conclusions}

In this study, the divided exhaust period (DEP) was implemented in a high-efficiency gasoline engine to evaluate the impact of the technology on various engine performance aspects. To this end, key design parameters of DEP components were optimized through 1D simulation, and detailed experimental verification and analysis were performed via engine dynamo tests. Some important results of this study can be summarized as follows:

1. GT power simulations were conducted to derive the optimized specifications of the turbocharger, exhaust cam profile, flow control valves, and a high low EGR system. By performing simulations while changing a major parameter of each element, specifications that can satisfy engine performance and fuel economy target could be determined. After the detailed design of DEP components with the optimized parameters, prototype DEP components were fabricated for experimental validation.

2. Through engine dynamometer tests, the DEP engine was confirmed to achieve the target performance set for application in electrified vehicle powertrains. The engine reached a maximum thermal efficiency of $42.5 \%$ and exhibited a wide sweet spot area, having efficiencies over $40 \%$, which is highly competitive when compared to conventional TGDI engines.

3. The improvement in BSFC due to the DEP implementation was approximately $3 \%$ at the lowest BSFC point mainly due to reduced pumping loss. In the DEP engine, pumping loss did not increase under high EGR flow conditions, but rather decreased, resulting in positive work. This confirmed the synergy between highly diluted combustion and DEP technology.

4. The feasibility of an improved catalyst-heating with DEP was confirmed through engine test under simulated cold-start conditions. Shutting off the exhaust flow in the blow-down port reduced the light-off time, as the exhaust gas bypassed the blow-down path with a higher heat capacity.

Author Contributions: Conceptualization, investigation, writing-original draft preparation, H.O.; conceptualization, investigation, writing — review and editing, D.J., D.R. and J.S. (Jerry Song); methodology, investigation, J.S. (Jinwook Son); conceptualization, supervision, S.W.; supervision, project administration, Y.K.; investigation, writing-original draft preparation J.H. All authors have read and agreed to the published version of the manuscript.

Funding: This research received no external funding.

Acknowledgments: The authors would like to thank Vitesco Technologies Korea for their kind support on the ECU logic development. 
Conflicts of Interest: The authors declare that they have no known competing financial interests or personal relationships that could have appeared to influence the work reported in this paper.

\section{References}

1. International Energy Agency. Energy Technology Perspectives 2020: Special Report on Clean Energy Innovation; OECD: Paris, France, 2020. Available online: https://www.oecd-ilibrary.org/energy/energy-technology-perspectives-2020_ab43a9a5-en (accessed on 20 September 2021). [CrossRef]

2. Hyundai Motor Company. Road to Sustainability-2020 Sustainability Report. 2020. Available online: https://www.hyundai. com/content/hyundai/ww/data/csr/data/0000000048/attach/english/hmc-2020-sustainability-report-en-v2.pdf (accessed on 20 September 2021).

3. Wukisiewitsch, W.; Danzer, C.; Semper, T. Systematical Development of Sustainable Powertrains for 2030 and Beyond. MTZ Worldw. 2020, 81, 30-37. [CrossRef]

4. Kaita, K. Diversified Electrification-The Key for Toyota's Challenge towards a Sustainable Society. In Proceedings of the 40th International Vienna Motor Symposium, Vienna, Austria, 15-17 May 2019.

5. Uhlmann, T.; Alt, N.; Lückmann, D.; Balazs, A.; Zwar, P.; Müller, A.; Thewes, M.; Frese, J. xHEV Concept Achieving 2030 CO 2 Targets. In Proceedings of the 42nd International Vienna Motor Symposium, Vienna, Austria, 29-30 April 2021.

6. Tsurushima, T. Future Internal Combustion Engine Concept Dedicated to NISSAN e-POWER for Sustainable Mobility. In Proceedings of the 29th Aachen Colloquium Sustainable Mobility, Aachen, Germany, 5-7 October 2020.

7. Kimura, S. Internal Combustion Engine Challenges for Carbon Neutral. J. Soc. Automot. Eng. Jpn. 2021, 75, 12-20.

8. Reitz, R.; Ogawa, H.; Payri, R.; Fansler, T.; Kokjohn, S.; Moriyoshi, Y.; Agarwal, A.K.; Arcoumanis, D.; Assanis, D.; Bae, C.; et al. IJER editorial: The future of the internal combustion engine. Int. J. Engine Res. 2020, 21, 3-10. [CrossRef]

9. Schoeffmann, W.; Howlett, M.; Fuerhapter, A.; Kapus, P. A Modular Gasoline Engine Family for Hybrid Powertrains: Balancing Cost and Efficiency Optimization. SAE Tech. Pap. 2020. [CrossRef]

10. Leduc, P.; Dubar, B.; Ranini, A.; Monnier, G. Downsizing of gasoline engine: An efficient way to reduce $\mathrm{CO}_{2}$ emissions. Oil Gas Sci. Technol. Rev. IFP. 2003, 58, 115-127. [CrossRef]

11. Han, D.; Han, S.; Han, B.; Kim, W. Development of 2.0 L Turbocharged DISI Engine for Downsizing Application. SAE Tech. Pap. 2007. [CrossRef]

12. Szengel, R.; Middendorf, H.; Voeltz, S.; Laumann, A.; Tilchner, L.; Theobald, J.; Etzrodt, T.; Krebs, R. Der TSI-Motor mit 90 kW. MTZ Motortech. 2007, 68, 538-545. [CrossRef]

13. Davis, S.C.; Boundy, R.G. Transportation Energy Data Book: Edition39. 2021. Available online: https://tedb.ornl.gov/wpcontent/uploads/2021/02/TEDB_Ed_39.pdf (accessed on 20 September 2021).

14. Oh, H.; Lee, J.; Woo, S.; Park, H. Effect of synergistic engine technologies for $48 \mathrm{~V}$ mild hybrid electric vehicles. Energy Convers. Manag. 2021, 244, 114515. [CrossRef]

15. Ikeya, K.; Takazawa, M.; Yamada, T.; Park, S.; Tagishi, R. Thermal Efficiency Enhancement of a Gasoline Engine. SAE Int. J. Engines 2015, 8, 1579-1586. [CrossRef]

16. Nakata, K.; Nogawa, S.; Takahashi, D.; Yoshihara, Y.; Kumagai, A.; Suzuki, T. Engine Technologies for Achieving $45 \%$ Thermal Efficiency of S.I. Engine. SAE Int. J. Engines 2016, 9, 179-192. [CrossRef]

17. Lee, B.; Oh, H.; Han, S.; Woo, S. Development of High Efficiency Gasoline Engine with Thermal Efficiency over $42 \%$. Pap. 2017, 1, 2229. [CrossRef]

18. Möller, C.; Johansson, P.; Grandin, B.; Lindström, F. Divided Exhaust Period-A Gas Exchange System for Turbocharged SI Engines. SAE Tech. Pap. 2005. [CrossRef]

19. Gundmalm, S.; Cronhjort, A.; Angstrom, H. Divided Exhaust Period: Effects of Changing the Relation between Intake, BlowDown and Scavenging Valve Area. SAE Int. J. Engines 2013, 6, 739-750. [CrossRef]

20. Bharath, A.; Reitz, R.; Rutland, C. Divided Exhaust Period Implementation in a Light-Duty Turbocharged Dual-Fuel RCCI Engine for Improved Fuel Economy and Aftertreatment Thermal Management: A Simulation Study. SAE Int. J. Engines 2018, 11, 1251-1272. [CrossRef]

21. Roth, D.; Keller, P.; Sisson, J. Valve-Event Modulated Boost System. SAE Tech. Pap. 2010. [CrossRef]

22. Roth, D.; Becker, M. Valve-Event Modulated Boost System: Fuel Consumption and Performance with Scavenge-Sourced EGR. SAE Int. J. Engines 2012, 5, 538-546. [CrossRef]

23. Roth, D.; Chen, W.; Ciaravino, J. Divided-Exhaust Turbocharger System with Boost-Valve. SAE Tech. Pap. 2018. [CrossRef]

24. Hu, B.; Akehurst, S.; Brace, C.; Copeland, C.; Turner, J. 1-D Simulation Study of Divided Exhaust Period for a Highly Downsized Turbocharged SI Engine-Scavenge Valve Optimization. SAE Int. J. Engines 2014, 7, 1443-1452. [CrossRef]

25. Hu, B.; Brace, C.; Akehurst, S.; Copeland, C.; Turner, J. Simulation Study of Divided Exhaust Period for a Regulated Two-stage Downsized SI Engine. SAE Tech. Pap. 2014. [CrossRef]

26. Gundmalm, S.; Cronhjort, A.; Angstrom, H. Divided Exhaust Period on Heavy-Duty Diesel Engines. In Proceedings of the THIESEL 2012 Conference on Thermo- and Fluid Dynamic Processes in Direct Injection Engines, Valencia, Spain, 11-14 September 2012. 
27. Kuhlbach, K.; Mehring, J.; Borrmann, D.; Friedfeldt, R. Cylinder head with integrated exhaust manifold for downsizing concepts. MTZ Worldw. 2009, 70, 12-17. [CrossRef]

28. Son, J.; Lee, S.; Han, B.; Kim, W. A Correlation between Re-Defined Design Parameters and Flow Coefficients of SI Engine Intake Ports. SAE Trans. 2004, 113, 750-757. [CrossRef] 